\title{
O COMPORTAMENTO ALTERNATIVO CONFORME AO DIREITO: COMENTÁRIOS À DECISÃO DO JUÍZO DE PRIMEIRO GRAU DO TRIBUNAL DE JUSTIÇA DO ESTADO DO MATO GROSSO DO SUL
} ALTERNATIVE BEHAVIOUR IN ACCORDANCE WITH THE LAW: COMMENTS TO THE MATO GROSSO DO SUL COURT DECISION

Renato Kramer

Universidade de Berlin - Alemanha

Leonardo Siqueira ${ }^{2}$

FADIC - PE

Resumo

O artigo aborda o grupo de caso comportamento alternativo conforme ao Direito à luz da decisão do juízo de primeiro grau, bem como do acórdão do Tribunal de Justiça do Estado do Mato Grosso do Sul. São apresentados e analisados os diversos posicionamentos a respeito da temática, discutindo-se sobretudo qual teoria deve ser aplicada - da evitabilidade ou a do aumento do risco. A temática aponta para embate doutrinário existente principalmente na doutrina alemã, tendo em vista que no Brasil doutrina e jurisprudência - o assunto ainda carece de uma discussão mais ampla, profunda e profícua. O trabalho visa evidenciar as vantagens teóricas e práticas na aplicação da teoria da imputação objetiva em relação à adotada no nosso país.

Palavras-chaves

Teoria da imputação objetiva. Comportamento alternativo conforme ao Direito. Teoria da evitabilidade. Teoria do aumento do risco.

\section{Abstract}

The article discusses the case group's alternative behavior in accordance with the law in libt of the decision of the first degree court, as well as the decision of the court of justice of the State of Mato Grosso do Sul.

1 Doutorando na Humboldt-Universität de Berlin. Mestre em direito penal pela Faculdade Damas da Instrução Cristã

2 Pesquisador visitante na Humboldt-Universität de Berlin (2019-2020). Professor do Programa de Pós-graduação em Direito da Faculdade Damas da Instrução Cristã. Doutor em direito penal pela UFPE. 
The various positions on the subject are presented and analyzed, discussing above all which theory should be applied - that of avoidability or that of increased risk. The theme aims to a doctrinal discussion existing mainly in German doctrine, considering that in Brazil - doctrine and jurisprudence - the subject still needs a wide, deeper and fruitful discussion. This paper will indicate the theoretical and practical advantages in the application of the objective imputation theory in relation to the adopted in our country.

\section{Keywords}

Objective imputation theory. Alternative behaviour in accordance with the law. Avoidability theory. Risk increase theory.

\section{INTRODUÇÃO}

O presente artigo pretende examinar um aspecto discordante dentro da teoria da imputação objetiva, a utilização da teoria do comportamento alternativo conforme o direito ou do critério da diminuição do risco. A teoria da imputação objetiva é em grande medida negligenciada pela doutrina brasileira, que prefere abordar a questão do procedimento jurídico para imputar o resultado como obra do agente em dois níveis: numa simples relação de causalidade; e no plano subjetivo da tipicidade. Não cabe aqui discutir os problemas teóricos - vários - decorrentes dessa opção. A teoria da imputação objetiva busca examinar o processo de imputação sob um viés normativo e objetivo, alterando o centro de gravitação para o desvalor da ação e a inserção do conceito de risco. Dois elementos são colocados na base do procedimento: a criação de um risco juridicamente relevante; e se o resultado pode ser imputado como concretização do risco criado pelo autor.

Esses dois elementos permitem a criação de alguns grupos de casos, dentre eles estão aqueles que podem ser examinados por duas doutrinas diversas: a diminuição do risco; ou o comportamento alternativo conforme o direito. Partirmos da hipótese que a teoria da evitabilidade é mais coerente na resolução dos problemas colocados e congruente nos seus pressupostos. 
Para colocarmos a nossa hipótese à prova, discutiremos as teorias com base em casos discutidos pela doutrina alemã e um caso real ocorrido no Brasil. No caso brasileiro, ocorrido no ano de 2012, o juízo de primeiro grau do Tribunal de Justiça do Estado do Mato Grosso do Sul e posteriormente a Segunda Câmara Criminal do Tribunal de Justiça ocuparam-se dessa questão e chegaram a um denominador comum: considerou-se que, no caso concreto, o agente havia agido com imprudência ao atropelar a vítima (I), sendo inaplicável o instituto da compensação de culpas no direito penal (II). O caso é especialmente interessante por dois aspectos: ambas as teorias que iremos abordar são utilizadas primordialmente para os crimes culposos; e, não menos importante, o caso demonstra uma complexidade aparentemente negligenciada na decisão judicial.

Vale ressaltar que essas decisões judiciais são alvo de intensa discussão na literatura alemã, na qual encontram-se juízos divergentes a respeito de qual teoria deve ser adotada para solucionar o correspondente grupo de caso. Não apenas pela polêmica e pela importância prática do tema, mas também pela dificuldade e pelo fascínio das questões dogmáticas que o envolvem, afigura-nos apropriado apresentar ao leitor brasileiro esse caso e as discussões judiciais e doutrinárias dele decorrentes.

Em linhas gerais, discutiremos se a decisão do juízo de primeiro grau merece aprovação e tentaremos identificar se os argumentos trazidos para se chegar ao resultado são ou não corretos. Para tanto, procederemos da seguinte forma: (I) descreveremos o caso concreto tal qual foi orquestrado pela justiça brasileira; (II) apresentaremos o teor e os argumentos dela; (III) traçaremos uma síntese da discussão doutrinária e casos concretos discutidos; e (IV) avançaremos nas nossas próprias considerações dogmáticas, para posteriormente resolvermos os casos aduzidos. 


\section{DESCRIÇÃO DO CASO}

O acusado $^{3}$ teria conduzido o seu veículo automotor com velocidade incompatível com o local por volta das $19 \mathrm{~h} 30 \mathrm{~min}$ e, em um determinado instante, não teria conseguido frear, colidindo com a vítima que estava atravessando a via em uma bicicleta, causando-a politraumatismo e, por conseguinte, a sua morte.

$\mathrm{Da}$ análise da sentença, destacamos os seguintes dados fáticos: (I) não havia nenhum tipo de sinalização para o veículo, indicando a velocidade máxima permitida para o local; (II) o réu não havia ingerido bebida alcoólica ou consumido qualquer substância entorpecente; (III) a vítima havia atravessado a avenida de forma inadequada, pois não havia qualquer indicação de travessia de pedestres; (IV) foi constatada uma frenagem de $19 \mathrm{~m}$ (dezenove metros) pertinente ao veículo envolvido; (V) a vítima foi arremessada a cerca de $27 \mathrm{~m}$ (vinte e sete metros); (VI) o veículo só parou a cerca de $21 \mathrm{~m}$ (vinte e um metros) do local da colisão; (VII) considerando o local com pavimento asfáltico e seco, extrai-se o coeficiente de atrito igual a 0,8; (VIII) de posse de todos os dados acima elencados, a velocidade em que se encontrava o veículo momentos antes da colisão era de $65 \mathrm{~km} / \mathrm{h}$ (sessenta e cinco quilômetros por hora); (IX) a velocidade máxima permitida para o local, por força do código de trânsito brasileiro, é de $40 \mathrm{~km} / \mathrm{h}$.

\section{A DECISÃO JUDICIAL}


O juiz de primeiro grau do Tribunal de Justiça do Estado do Mato Grosso do Sul condenou o acusado por homicídio culposo, conforme o art. 302, caput, do código de trânsito brasileiro.

Utilizando-se dos trabalhos da perícia o magistrado cita em sua decisão que o autor do fato teria conduzido o seu veículo até o momento da colisão a uma velocidade de $65 \mathrm{~km} / \mathrm{h}$. A defesa alegou que por se tratar de uma "via arterial" a velocidade permitida para o local seria de até $60 \mathrm{~km} / \mathrm{h}$. O julgador, no entanto, refuta tal alegação da defesa, asseverando que não há nenhum elemento nos autos que conclua que a via onde ocorreu o acidente seja uma "via arterial", em que seria permitida uma velocidade de $60 \mathrm{~km} / \mathrm{h}$. Segundo o CTB via arterial é "aquela caracterizada por interseções em nível, geralmente controlada por semáforo, com acessibilidade aos lotes lindeiros e às vias secundárias e locais, possibilitando o trânsito entre as regiões da cidade". O juiz com base na perícia do caso afirma, porém, tratar-se de uma via coletora, cujo acesso pode ocorrer por meio de uma via arterial. Segundo o $\mathrm{CTB}^{4}$, via coletora "é aquela destinada a coletar e distribuir o trânsito que tenha necessidade de entrar ou sair das vias de trânsito rápido ou arteriais, possibilitando o trânsito dentro das regiões da cidade".

Dessa forma, o acusado estava em velocidade acima do legalmente permitido. O magistrado como fundamentação ainda

4 CTB:Art. 61. A velocidade máxima permitida para a via será indicada por meio de sinalização, obedecidas suas características técnicas e as condições de trânsito. $\int 1^{\circ}$ Onde não existir sinalização regulamentadora, a velocidade máxima será de: I - nas vias urbanas: a) oitenta quilômetros por hora, nas vias de trânsito rápido: b) sessenta quilômetros por hora, nas vias arteriais; c) quarenta quilômetros por hora, nas vias coletoras; d) trinta quilômetros por hora, nas vias locais. 
asseverou que: (I) o acusado teria afirmado não ter dado tempo de frear, do que se constata que ele estava em alta velocidade, pois se tivesse conduzido o veículo em velocidade compatível, teria tido tempo de frear ou ao menos, diminuir o impacto; (II) a testemunha do incidente confirmou que o acusado estava correndo, inclusive estimou a velocidade em aproximadamente $100 \mathrm{~km} / \mathrm{h}$; (III) a vítima teria sido arremessada a cerca de 04 a 05 metros de altura e 27 metros do local do acidente, podendo-se concluir que a velocidade era realmente alta; (IV) o impacto foi tão repentino que a testemunha afirma que a vítima deve ter acreditado que não viu o carro ou que dava para ter atravessado, tudo indicando que o acusado chegou muito rápido até ela e, talvez, até com má iluminação do veículo, pois caso tivesse sido boa, quiçá tivesse visto o pedestre e este visto o carro e (V) a frenagem foi de 19 metros, tendo o veículo parado a cerca de 21 metros do local da colisão.

O magistrado, rejeitando a tese da defesa da culpa exclusiva da vítima, afirmou que ela só se aplica caso se comprove que o agente não tenha contribuído, de nenhuma forma, para a ocorrência do acidente.

Por fim, concluiu o julgador que os elementos do crime culposo estão presentes, de modo a atribuir a responsabilidade penal do agente. Senão vejamos: (I) a conduta humana voluntária comissiva - direção de veículo automotor; (II) Inobservância de um dever objetivo de cuidado na modalidade imperícia - tráfego de veículo automotor em velocidade incompatível para o local; (III) resultado lesivo não desejado - morte; (IV) nexo de causalidade entre a conduta do agente que deixa de observar o seu dever de cuidado e o resultado dela advindo - a morte decorreu da conduta imprudente do acusado ao dirigir em excesso de velocidade numa via urbana; (V) 
Previsibilidade - o acusado podia, nas circunstâncias em que se encontrava, ter como possíveis as consequências do seu ato.

\section{GRUPO DE CASOS E ANÁLISE DOUTRINÁRIA}

Como já anteriormente colocado, o grupo de caso a ser analisado não é explorado pela doutrina penal brasileira. Isso remetenos a argumentar com base na doutrina penal alemã, onde a temática é demasiadamente discutida. Mas, o que quer dizer comportamento alternativo conforme ao Direito? Ilustremos com alguns exemplos extraídos e breves comentários da literatura estrangeira e, sobretudo alemã, para melhor entendê-lo.

Segundo Jorge de Figueiredo Dias há casos em que o bem jurídico protegido já se encontra ameaçado, mas por outras forças acaba-se aumentando esse risco, como, por exemplo, no caso de uma ambulância que, em virtude de uma manobra errada, causa a morte do paciente que transportava e que, em todo o caso, já se encontrava em péssimo estado em virtude de um enfarte do miocárdio. Em casos como este, difícil é decidir, ex post, se o resultado morte deve ser imputado ao perigo "enfarte ou ao perigo "acidente rodoviário". Se a resposta for a de que, mesmo que o acidente não tivesse se verificado, o doente possivelmente, ou provavelmente, ou até mesmo com quase certeza teria morrido, deve continuar a afirmar-se a imputação objetiva à conduta defeituosa de condução do motorista da ambulância? Trata-se aqui do que ficou conhecido como a doutrina dos comportamentos ilícitos alternativos. $^{5}$ 
Nessa trilha, em delitos de negligência exerce o nexo de infração ao dever ou também chamado de nexo de violação das obrigações um papel central para se responsabilizar o autor. Isso ocorre mediante o comportamento do autor (violador), que criou um risco, o qual não se manifesta no resultado, quando este, também com o comportamento alternativo conforme ao dever tivesse se realizado com a segurança de uma probabilidade aproximativa ${ }^{6}$.

Continuemos com os casos.

(1)"A" dirige seu carro com velocidade alta em uma localidade. De repente cambaleia o bêbado "B" perante o veículo. "B" vem a morrer em razão do acidente. "A" não conseguiria frear a tempo, mesmo que observasse a velocidade permitida. ${ }^{7}$

(2)O Médico clínico "A" concede ao paciente "B" a saída temprária, o que possibilita a perpetração de um delito de homicídio em relação a "O". A concessão da licença domiciliária vai contra a regra de cuidado, porque já se havia realizado nas saídas anteriores estupros tentados. Assim, o médico excedeu-se na análise do seu campo de ação. "A" pensou, porém, não ter incorrido em responsabilidade, porque "P", do contrário, teria fugido mediante o friso de grade entortado e, assim, poderia cometer o homicídio ${ }^{8}$.

(3)Exemplo segundo o BGH: O ciclista "R" vem a óbito, quando um caminhão com reboque "L" o ultrapassa com uma

brasileira. $2^{a}$ edição portuguesa, Coimbra: Editora Revista dos Tribunais. 2007, p. 335337.

6 WESSELS; BEULKE; SATZGER. Strafrecht: Allgemeiner Teil. 45 Auflage. Heidelberg: Müller, 2015, p. 88.

7 WESSELS; BEULKE; SATZGER. Strafrecht: Allgemeiner Teil. 45 Auflage. Heidelberg: Müller, 2015, p. 88.

8 WESSELS; BEULKE; SATZGER. Strafrecht: Allgemeiner Teil. 45 Auflage. Heidelberg: Müller, 2015, p. 88. 
distância lateral pequena. "R" estava consideravelmente bêbado, havendo motivo para a aceitação de que ele também teria caído debaixo do veículo, se "L" tivesse respeitado a distância segura exigida. ${ }^{9}$

(4)Enrique Gimbernat Ordeig, por outro lado, nos dá um exemplo muito interessante ocorrido em Salamanca, na Espanha: uma paciente vinha sofrendo há anos de uma bronquite asmática. Para combater essa enfermidade havia sido prescrito à paciente a aplicação de uma vacina de um extrato hipossensibilizante de ácaros, mediante injeções subcutâneas, de doses progressivamente crescentes. E para conseguir a finalidade desejada é estritamente necessário que se respeitem a dose e intervalos de aplicação estabelecidos. O hospital se expressou claramente que a vacina será posta seguindo rigorosamente o esquema de tratamento seguinte, no que diz respeito a doses, número de injeções e frequência de administração. Começará com 0,05 cc e irá aumentando a 0,1, 0,2, 0,4, 0,7 cc. Será aplicada uma dose a cada duas semanas. Alcançada a dose de $0,7 \mathrm{cc}$, continuará com ela, sem aumentá-la, até terminar o frasco. A partir da dose $0,7 \mathrm{cc}$, sua administração se efetuará uma vez ao mês. Como entre as doses administradas antes de 0,5 cc e a que causou a morte da paciente foi transcorrido dois meses e meio, houve a necessidade de voltar a iniciar a imunoterapia com a dose mínima de 0,05 - isso porque, se há o distanciamento de intervalos entre doses, o nível de igG decresce até o ponto de dever iniciar o processo de imunoterapia de novo com a dose mínima inicial. Não obstante isso, fora aplicada à paciente uma dose de 0,4 cc,

9 WESSELS; BEULKE; SATZGER. Strafrecht: Allgemeiner Teil. $45^{\mathrm{a}}$ Auflage. Heidelberg: Müller, 2015, p.89. 
estabelecendo-se na sentença que a causa da morte da paciente fora uma parada cardiorrespiratória derivada de uma reação anafilática ou de tipo anafilactoide provocada pela dose vacinal que havia sido ministrada momentos antes. Vê-se, nesse caso concreto, que a dose de 0,05, de acordo com a lex artis, após dois meses e meio, não foi aplicada. Entretanto, pôde deduzir-se que a administração dessa vacina encerrava certos riscos, já desde a sua dose inicial, que tratavam de evitá-las com toda uma série de precauções, e isso porque a complicação de um choque anafilático, segundo a sentença, pode produzir-se ainda em hipóteses de administração correta, se bem que com mais frequência se não se respeita a pauta de administração da imunoterapia ou se alteram as doses. ${ }^{10}$

(5)Outro caso é o do farmacêutico (1887), o qual vendeu à mãe de uma criança enferma, sem a respectiva receita médica, um medicamento - composto de fósforo -, tendo sido ainda vendido por mais quatro vezes. A criança morreu em consequência da administração do preparado, mas foi possível demonstrar que o médico teria renovado a receita caso a mãe tivesse solicitado, tendo em vista ser o tratamento padrão para aquela enfermidade. ${ }^{11}$

(6)É apresentado também o caso da novocaína (1926), a respeito do qual o médico empregou cocaína para anestesiar localmente uma criança, omitindo utilizar a novocaína - como exigia a lex artis -, morrendo o paciente em virtude da anestesia e de sua

10 GIMBERNAT ORDEIG, Enrique. El comportamiento alternativo conforme a derecho: de la causalidad a la imputación objetiva. Espanha: editorial de MontividéoBuenos Aires, 2017, p. 1-3.

11 GIMBERNAT ORDEIG, Enrique. El comportamiento alternativo conforme a derecho: de la causalidad a la imputación objetiva. Espanha: editorial de MontividéoBuenos Aires, 2017, p. 8. 
disposição física desfavorável. Pôde-se afirmar que muito provavelmente a criança teria falecido também se houvesse aplicado a novocaína de forma adequada. ${ }^{12}$

A partir de agora iremos abordar as duas teorias que buscam fundamentar a correta aplicação dentro desse grupo de casos: a teoria da evitabilidade; e a teoria do aumento do risco.

\subsection{Teoria da evitabilidade}

A opinião dominante na Alemanha pergunta se o resultado era evitável (Vermeidbarkeitstheorie). Para ela se o resultado tivesse ocorrido da mesma forma com o comportamento alternativo conforme ao dever, deveria ser utilizado o princípio in dubio pro reo (na dúvida em favor do réu). Isso significa que o autor do resultado, dessa forma, não poder ser acusado, se em relação à evitabilidade restassem dúvidas na efetivação, ou seja, se existissem pontos de fundamento concretos que no comportamento alternativo conforme ao Direito tivesse ainda assim o resultado ocorrido. ${ }^{13}$

De acordo com esta perspectiva, o resultado deve ser plasmação da falta de cuidado. Por outro lado, se o resultado segue produzindo ainda com um comportamento prudente, a infração da norma de cuidado não foi determinante. Entre outras razões, tem-se falado que, negando-se tal raciocínio careceria de importância o

12 GIMBERNAT ORDEIG, Enrique. El comportamiento alternativo conforme a derecho: de la causalidad a la imputación objetiva. Espanha: editorial de MontividéoBuenos Aires, 2017, p. 8.

13 WESSELS; BEULKE; SATZGER. Strafrecht: Allgemeiner Teil. 45 Auflage. Heidelberg: Müller, 2015, p.89. 
comportamento imprudente do sujeito sempre que se demonstrasse que o resultado continua se produzindo; adicionalmente, a impossibilidade de constatar que o resultado não teria se produzido levaria a uma absolvição na maioria dos casos com base no princípio in dubio pro reo. ${ }^{14}$

\subsection{Teoria do aumento do risco}

Há casos, nos quais, por exemplo, um risco criado por um comportamento contrário ao direito (no tráfego) mesmo assim não é aumentado em comparação com o comportamento correto. Então, o agente violador do dever objetivo de cuidado que ultrapassa o risco do comportamento cria, em verdade, apenas um perigo, o qual é evidenciado na ponderação de interesses como um perigo tolerado do tráfego: um risco permitido. ${ }^{15}$

Nesse sentido, trata-se aqui da questão se a morte do ciclista $\mathrm{R}$, ultrapassado por $\mathrm{L}$ com pouca distância de segurança, pode ser atribuída ao motorista de caminhão L, mesmo considerando que haja razão para acreditar que, mesmo que $L$ tivesse se comportado de acordo com seu dever, a morte de $\mathrm{R}$ não poderia ter sido evitado por causa de seu estilo de condução inseguro induzido pelo álcool. Este problema já suscita fricções consideráveis, que devem ser combatidas de forma mais adequada com a teoria do aumento do risco num direito penal que protege bens jurídicos. Assim, não há

14 LARRAURI, Helena. Notas preliminares para uma discussão sobre a imputação objetiva. Espanha: ADPCP, T.XLI, Fasc.III, Septiembre-Diciembre 1988, p. 750.

15 KÜPER, Wilfried. Überlegungen zum sog. Pflichtwidrigkeitszusammenhang beim Fahrlässigkeitsdelikt. Berlin: Walter de Gruyter, p. 277. 
razão para libertar o infrator do risco e absolvê-lo se o sucesso ocorrer como efeito do perigo inerente à ultrapassagem. ${ }^{16}$

Assim, para além do nexo de causalidade entre a ação e o resultado, exige-se uma outra relação entre a violação do dever e o resultado, ou seja, um aumento do risco. ${ }^{17}$ Por outro lado, o risco juridicamente proibido não se realiza no resultado se, nas circunstâncias concretas, o risco da ocorrência do resultado no caso de um comportamento ilicitamente perigoso por parte do perpetrador não era, em última análise, mais elevado do que no caso de um comportamento alternativo lícito. Para a afirmação de uma realização do risco, era assim necessário que o aumento do perigo ex ante investido na ação delituosa continuasse também a ter um efeito ex post como um aumento do perigo para o resultado concreto. ${ }^{18}$ Ou seja, trata-se de identificar sob quais requisitos ex post pode ser falado da realização de um perigo proibido criado mediante uma ação ${ }^{19}$, de modo que o aumento do perigo deve realmente ser constatado, não bastando que ele pareça simplesmente possível. ${ }^{20}$

16 HEFENDEHL, Roland. Objektive Zurechnung bei Rechtfertigunsgründen? Begründbarkeit und Grenzen, Festschrift für Wolfgang Frisch, Berlin: Duncker und Humboldt GmbH, p. 471.

17 SCHAFFSTEIN, Friedrich. Die Risikoerhöhung als objektives Zurechnungsprinzip im Strafrecht, insbesondere bei der Beihilfe, Festschrift für Richard Honig, Göttingen: Schwartz, 1970, p. 172.

18 SCHMOLLER, Kurt. Verwirklichung einer unerlaubten Gefahr bei Risikoerhöhung, Festschrift für Jürgens Wolter, Berlin: Duncker und Humboldt GmbH, 2013, p. 480.

19 SCHMOLLER, Kurt. Verwirklichung einer unerlaubten Gefahr bei Risikoerhöhung, Festschrift für Jürgens Wolter, Berlin: Duncker und Humboldt GmbH, 2013, p. 485.

20 STRATENWERTH, Günter. Bemerkungen zum Prinzip der Risikoerhöhung, Festschrift für Wilhelm Gallas zum 70. Geburtstag, Berlin: Walter 


\subsection{TOMADA DE POSIÇÃO E RESOLUÇÃO DOS CASOS}

A teoria do aumento do risco não nos parece o posicionamento mais adequado para a resolução do grupo de casos tratados. O primordial problema dessa teoria se refere à impossibilidade de se traçar critérios minimamente seguros que estabeleceriam o grau a partir do qual o aumento do risco elevaria a chance da ocorrência do resultado. Nesse sentido, a solução que Roxin propõe à questão, ou seja, há um aumento do risco quando se "verificar, com base no conhecimento ex post, se a norma formulada ex ante ainda pode ser tida como uma proibição racional e redutora do risco no resultado" 21 , não é convincente, principalmente quando falamos em normas de trânsito. Essas normas visam sempre - tendo em vista que o transporte rodoviário é uma atividade de perigos inerentes e inexoráveis - estabilizar os possíveis riscos da atividade e estabelecer os limites que devem ser suportados pela sociedade. Nesse sentido toda a norma de trânsito, em comparação com o cenário de ausência de regulamentação, tende a diminuir os riscos da atividade, o que nos levaria na prática - se adotássemos o posicionamento de Roxin - a considerar todas as violações às normas de trânsito como aumento do risco na ocorrência do resultado, tendo em vista que elas são criadas, como afirmamos, para diminuir os perigos. As únicas hipóteses para exclusão da imputação,

de Gruyter, 1973, p. 235.

21 ROXIN, Claus. Funcionalismo e imputação objetiva no direito penal. Rio de Janeiro: Renovar, 2002， p.339-343 


\section{DELICTAE, Vol. 4, Nº, Jan..-Jun. $2019 \mid 102$}

ainda segundo o autor, ocorreriam quando a norma se demonstrasse em concreto inócua ou inidônea.

O caminho que adotamos, a teoria da evitabilidade, leva em consideração para a imputação do resultado como obra do agente a comprovação do seu nexo com o comportamento do autor - risco desaprovado juridicamente. Assim, o resultado só pode ser imputado como decorrente do risco do agente se há uma factual certeza que o comportamento conforme as normas evitaria o dano, criando assim uma vinculação - nexo - entre o resultado e a conduta que infringe o dever. Quando um acidente ocorre por excesso de velocidade do agente e a perícia comprova a sua não ocorrência com a observância à norma, a decisão judicial que condena o agente demonstra um nexo concreto entre o resultado e o risco criado - da mesma forma cumpre a função de estabilizar a expectativa referenciada.

No caso 1, por exemplo, constatou-se que o comportamento alternativo conforme o direito não teria evitado o acidente. Sem dúvida, a decisão judicial absolvendo o agente é a mais acertada, em consonância com a ideia que o resultado não se materializou no risco criado - nesse ponto as duas teorias aqui examinadas chegam a mesma resposta.

Por outro lado, o grande embate doutrinário se refere aos exemplos 3,4,5 e 6.Nesses casos, a priori, a teoria da evitabilidade toma um rumo diferente em comparação com a teoria do aumento do risco. Nesses casos, o princípio da presunção de inocência cumpre uma função primordial e soma-se a argumentação exposta na adoção da teoria da evitabilidade. Comumente a presunção de inocência é utilizada no âmbito do processo penal como um critério abalizador, estabelecendo a (in)suficiência das provas para fundamentar as decisões judiciais penais. Todavia a presunção de inocência cumpre também uma função importante no direito penal 
como um critério hermenêutico na interpretação dos tipo penais. No 3 caso, por exemplo, o motorista infringiu uma regra de trânsito ao não manter uma distância segura em relação ao ciclista, contudo o resultado ocorreria com um alto grau de certeza, tendo em vista as circunstâncias do caso e entre elas o fato do ciclista estar bêbado. É nesse ponto que esse caso se diferencia do primeiro. A perícia não conseguiu constatar se a morte ocorreria necessariamente, apesar da alta probabilidade. Para os adeptos da teoria do aumento do risco, o agente precisaria ser responsabilizado. Segundo os autores que adotam a teoria da evitabilidade o motorista deveria ser absolvido, pois o comportamento alternativo conforme o direito não garantiria a inocorrência do resultado e, utilizando-se do princípio da presunção de inocência, o acusado não poderia ser condenado.

É nesse contexto que a presunção de inocência deve funcionar. Se existe uma alta probabilidade do mesmo resultado ocorrer - partindo de uma forte base factual - com o comportamento alternativo conforme o direito, a presunção de inocência afirmará a sua "ocorrência jurídica" e consequentemente o resultado não poderá ser imputado à conduta que violou o dever.

Já no caso 2 chegamos a uma conclusão diferente. A afirmação do médico que o paciente conseguiria fugir - tendo em vista a falha na segurança do hospital - mesmo que ele não concedesse a licença domiciliar, não é suficiente para excluir a imputação porquanto não se pode pressupor que a vítima morreria se o médico proibisse a saída. Nesse caso não há amparo factual para evocar o princípio da presunção de inocência e afirmar que o comportamento alternativo levaria com um alto grau de probabilidade ao mesmo resultado.

\section{CONCLUSÃO}




\section{DELICTAE, Vol. 4, Nº, Jan..-Jun. $2019 \mid 104$}

A teoria da imputação objetiva demonstrou ao longo dos anos a sua superioridade teórica e prática em comparação à sistemática adotada pela legislação penal brasileira. Como afirmarmos na introdução do trabalho, a sistemática prevista no código penal é simples e pouco complexa, buscando estabelecer no plano da tipicidade um nexo de causa e efeito e uma vinculação subjetiva entre o autor e o resultado. A decisão brasileira exposta demonstra a simplicidade que o caso é julgado e imputado a responsabilidade ao autor pelo resultado. Em um dado momento da fundamentação o juiz - ao falar que a perícia comprovou a velocidade acima da permitida - decidiu todo o processo de atribuição com a seguinte afirmação: "Observa-se, portanto, que o acusado agiu com culpa". Sem dúvida a culpa não é do magistrado; a conclusão é a lógica de um procedimento simples que se completou no caso em concreto com o exame dos requisitos do crime culposo. Com isso, ultrapassou-se a barreira da tipicidade e todas as questões que poderiam ser levantadas e problematizadas dissolveram-se na frugalidade do exame.

A teoria da imputação objetiva deslocou a problemática da imputação para o desvalor da ação, tomando como ponto central a criação de um risco juridicamente desaprovado e a sua realização no resultado. Superada essa barreira poderíamos analisar a tipicidade subjetiva. Nessa perspectiva, a decisão do juiz teria suprimido uma parte importante e considerável do processo de atribuição. Utilizando-se dessa teoria, poderíamos sucintamente falar que o agente criou um risco juridicamente desaprovado, tendo em vista $\mathrm{o}$ excesso de velocidade no momento do acidente. Nada a se questionar. Por outro lado, questões intrigantes emergem quando 


\section{DELICTAE, Vol. 4, No6, Jan..-Jun. $2019 \mid 105$}

passamos a examinar se o risco juridicamente desaprovado se materializou no resultado ocorrido.

Como se depreende da exposição doutrinária e resolução dos casos, adotamos a teoria da evitabilidade, o que nos leva a criticar uma ideia quase unânime na doutrina brasileira: a compensação de culpas. Quando se fala em compensação de culpas, inclusive argumentada na decisão judicial, afirma a doutrina que não é possível excluir a culpa do autor mesmo que se comprove a culpa concorrente da vítima. Somente em casos de culpa exclusiva da vítima, teríamos a exclusão da responsabilidade penal do autor. Em sentido contrário, a teoria da evitabilidade examina a conduta da vítima e a possibilidade de excluir a atribuição do resultado como obra do autor em determinados casos, tornando-se imprescindível questionar se o comportamento alternativo conforme o direito evitaria ou não o resultado. Em nenhum momento do processo se perquiriu sobre a conduta da vítima e a sua importância na ocorrência do resultado, na verdade sabe-se muito pouco sobre a vítima, onde ela estava, se tinha ingerido bebida alcoólica, etc. Nesse espeque, outra lacuna é irremediavelmente constatada: não se questionou a perícia, com base em todos os fatores do caso em concreto, se o comportamento alternativo conforme o direito evitaria concretamente e acima de qualquer dúvida factualmente razoável o resultado.

Com todas essas questões esquadrinhadas, buscamos mostrar a complexidade de um caso tratado artificialmente como simples e de fácil resolução devido às falhas do ordenamento jurídico brasileiro. A teoria da evitabilidade e do aumento do risco como toda a teoria da imputação objetiva - concede ao julgador uma poderosa lente multifocal que permite desanuviar o horizonte e 
ampliar a perspectiva na análise do fato delituoso.

\section{REFERÊNCIAS}

FIGUEIREDO DIAS, Jorge. Direito penal: parte geral. Tomo I. $1^{\mathrm{a}}$ edição brasileira. $2^{a}$ edição portuguesa, Coimbra: Editora Revista dos Tribunais, 2007.

GIMBERNAT ORDEIG, Enrique. E1 comportamiento alternativo conforme a derecho: de la causalidad a la imputación objetiva. Espanha: editorial de Montividéo-Buenos Aires, 2017.

HEFENDEHL, Roland. Objektive Zurechnung bei Rechtfertigunsgründen? Begründbarkeit und Grenzen, Festschrift für Wolfgang Frisch, Berlin: Duncker und Humboldt GmbH, 2013.

KÜPER, Wilfried. Überlegungen zum sog.

Pflichtwidrigkeitszusammenhang beim Fahrlässigkeitsdelikt. Berlin: Walter de Gryter, 1987

LARRAURI, Helena. Notas preliminares para uma discussão sobre a imputação objetiva. Espanha: ADPCP, T.XLI, Fasc.III, SeptiembreDiciembre 1988.

SCHAFFSTEIN, Friedrich. Die Risikoerhöhung als objektives Zurechnungsprinzip im Strafrecht, insbesondere bei der Beihilfe, Festschrift für Richard Honig, Göttingen: Schwartz, 1970.

SCHMOLLER, Kurt. Verwirklichung einer unerlaubten Gefahr bei Risikoerhöhung, Festschrift für Jürgens Wolter, Berlin: Duncker und Humboldt GmbH , 2013.

STRATENWERTH, Günter. Bemerkungen zum Prinzip der Risikoerhöhung, Festschrift für Wilhelm Gallas zum 70. Geburtstag, Berlin: Walter de Gruyter, 1973. 
ROXIN, Claus. Funcionalismo e imputação objetiva no direito penal. Rio de Janeiro: Renovar, 2002.

WESSELS; BEULKE; SATZGER. Strafrecht: Allgemeiner Teil. $45^{\mathrm{a}}$ Auflage. Heidelberg: Müller, 2015. 